\title{
Online Visualisation
}

\author{
Jiř́ Pánek and Jaroslav Burian
}

\begin{abstract}
This chapter deals with online tools used for spatial data visualisation. Currently, there exist many tools and software that can be used for this purpose, both commercial (e.g. ArcGIS Online) and non-commercial (e.g. MapBox, Leaflet or CartoDB). Within this chapter, we are focusing on the most used software solutions. The text serves the basic overview of existing solutions, that can be used with no or minimal programming skills.
\end{abstract}

\section{Keywords}

Visualisation · Online · Web · GIS · Maps

\subsection{Introduction}

The use of online mapping and spatial search has become ubiquitous, with hundreds of millions of desktop and smartphone users regularly accessing mapping services (Smith 2016). There is various numbers of platforms, that allow creating online maps without the need of coding knowledge. This section will firstly focus on the commercial online

J. Pánek $(\bowtie)$

Department of Development and Environmental Studies, Palacký University Olomouc, Olomouc, Czech Republic e-mail: jiri.panek@upol.cz

\section{J. Burian}

Department of Geoinformatics, Palacký University

Olomouc, Olomouc, Czech Republic

e-mail: jaroslav.burian@upol.cz
GIS applications from Esri called ArcGIS Online (https://www.arcgis.com/home/index.html), Collector for ArcGIS and platform Story Maps (http://storymaps.arcgis.com/en/). Furthermore, other platforms such as Leaflet, MapBox, or CartoDB will be briefly described as well.

\subsection{ArcGIS Online}

ArcGIS online a cloud-based mapping and analysis platform from Esri (Esri 2018a), that allows users to access the workflow-specific apps, maps and data from around the globe, and tools for being mobile in the field (Pánek and Glass 2018). In order to use ArcGIS online platform, one has to have a login - it can be either ArcGIS Public Account or Enterprise login (Esri Account). The Public Account is free, but has some limitations, such as users with Public Account cannot publish Feature Services from ArcGIS Desktop to a Public Account. It is possible to upload shape files that are available as layers (so long as not greater than 1000 features) and total storage limit is 2GB. On the other hand, the Enterprise login is less restricted, but usually available only to institutions, who pay for it. The data and maps are stored in a cloud, hence can be access from anywhere and anytime. The interface of ArcGIS online (Fig. 10.1) resembles other web mapping platforms, and allows users to upload offline data in a form:

- Shapefile (ZIP archive containing all shapefile files) 


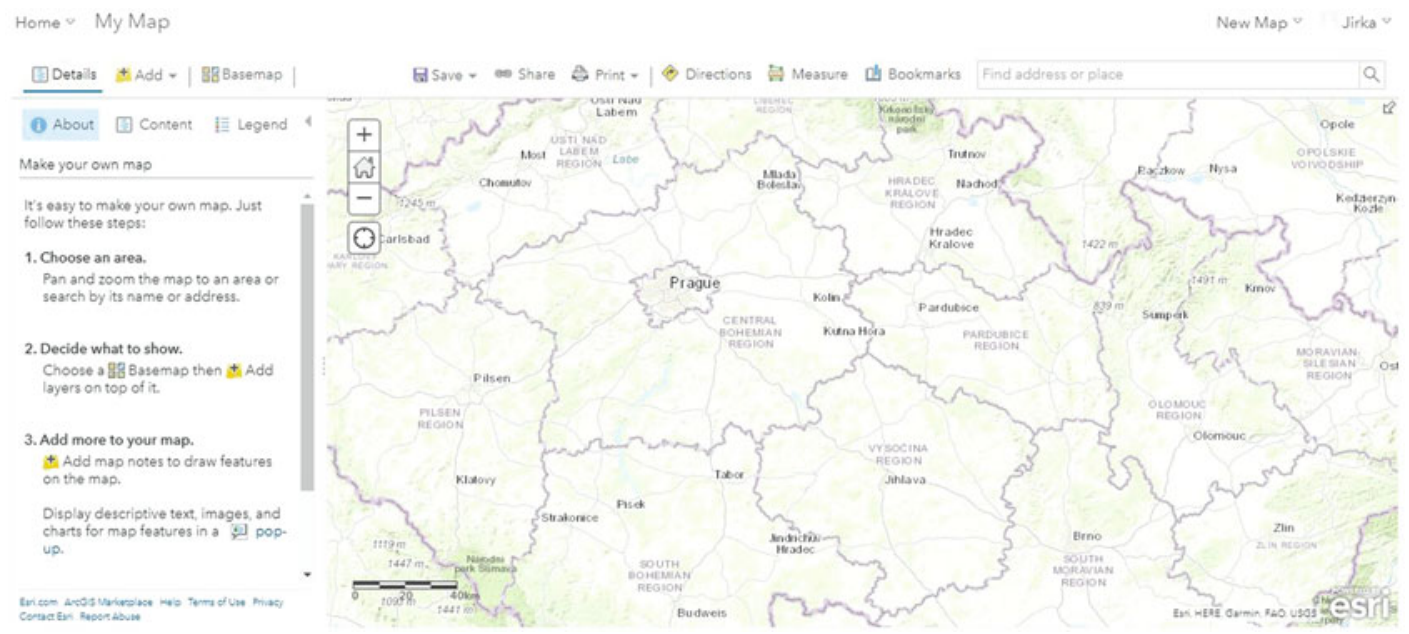

Fig. 10.1 Interface of ArcGIS Online. (Source: Authors)

- CSV or TXT files with optional address, place or coordinate locations (comma, semi-colon or tab delimited)

- GPX (GPS Exchange Format)

- GeoJSON (open standard format for simple geographical features).

Furthermore, online data can be linked as ArcGIS Online layers, ArcGIS Server web services, OGC WMS/WMTS/WFS, Tile layers, KML files or GeoRSS files.

ArcGIS online is not just a tool for creating online maps, it gauges users with options to make web apps or 3D web scenes - with none or limited coding skills.

\subsection{Collector for ArcGIS}

Another Esri application usable for spationomy research, or field research in general, is Collector for ArcGIS - a stand-alone Esri mobile application available for use with iOS, Android, and Windows. Collector for ArcGIS is an application for designing field survey apps. Unfortunately, the user needs an ArcGIS organizational account to make full use of the application. Previous studies note the utility of Collector for educational applications, including geography classrooms (Peirce 2016; Kolvoord et al. 2017; Pánek and Glass 2018) and field trips (Cho and Kang 2017), typical topics for Collector deployment include also mapping ecosystem services (Edsall et al. 2015) and cadastral mapping (Mourafetis et al. 2015; Apostolopoulos et al. 2016). Collector is used less frequently for social and cultural applications, despite its possibilities for aggregating data on social and physical phenomena from multiple active field researchers. Similar to Collector capabilities is a Crowdsource Story Map template (Esri 2018b), that is unfortunately no more an active project and wont be developed in the future (ArcGIS Blog 2018).

There also exists free and open source alternative to Collector for ArcGIS - Open Data Kit (ODK) which is available at https://opendatakit. org/. ODK allows to design a survey for data collection and later collect spatial and non-spatial data in the field. Open-source alternative to Collector can be QField (https://www. qfield.org/) - data collection application for Android devices directly linked with QGIS.

\subsection{Esri Story Maps}

Esri Story Maps let you combine authoritative maps with narrative text, images, and multimedia content. They make it easy to harness the power of maps and geography to tell your story. Using StoryMaps for presenting study materials is becoming popular in recent years (Kerski 2015), in fields like history 
(Abrate et al. 2013; Coleman et al. 2015), but also migration (Kerski 2013) or protections of ecosystems (Crocker et al. 2015; Fox 2016).

First of all user needs to sign-in by using ArcGIS account either the institutional or public (free). One can also use Facebook or Google to log-in, nevertheless the public accounts have some limitations - especially in storage and some in functionality as well.

There are several templates one can use for creating his/her own online map presentation. In this section we will focus on two of the easier templates. The first template is "Shortlist" (see Fig. 10.2) and this template presents a set of photos or videos along with captions, linked to an interactive map. It's ideal for walking tours or any sequence of places one would like users to follow in order. The only thing author needs is to link photos from online repository (in case of free account) or upload photos (in case of paid account). If the pictures are geocoded - they have GPS coordinate included in the picture information, for example from smartphone, they will automatically appear on the map. In case they do not contain this information, one can easily place them manually on the map, by clicking at the picture and then clicking on the map, where the picture was taken. Once all the pictures are located, it is possible to edit captions, texts, labels, etc. Final version of the map is saved in the cloud - no need to download anything and is available online anytime.

The second map template presented in this section is "Story Map Journal", that is a bit more sophisticated and allows creating an in-depth narrative organized into sections presented in a scrolling side panel. As users scroll through the sections in your Map Journal they see the content associated with each section, such as a map, 3D scene, image, video, etc. Each "page" of the journal is built from two parts - stage (very often a map) and side panel (usually a text). Maps that are in the stage area can be pre-created, or you can create them during the process. In the side panel one can insert any text and link words in the text to webpages, photos, videos or even to a maps (Fig. 10.3). Nevertheless, Esri announced new version of StoryMaps, that will not support any of the "old" templates showed in this chapter.

\subsection{Google Fusion Tables}

Google Fusion Tables is a cloud-based service for data management and integration (Gonzalez et al. 2010). There can be found many examples of use

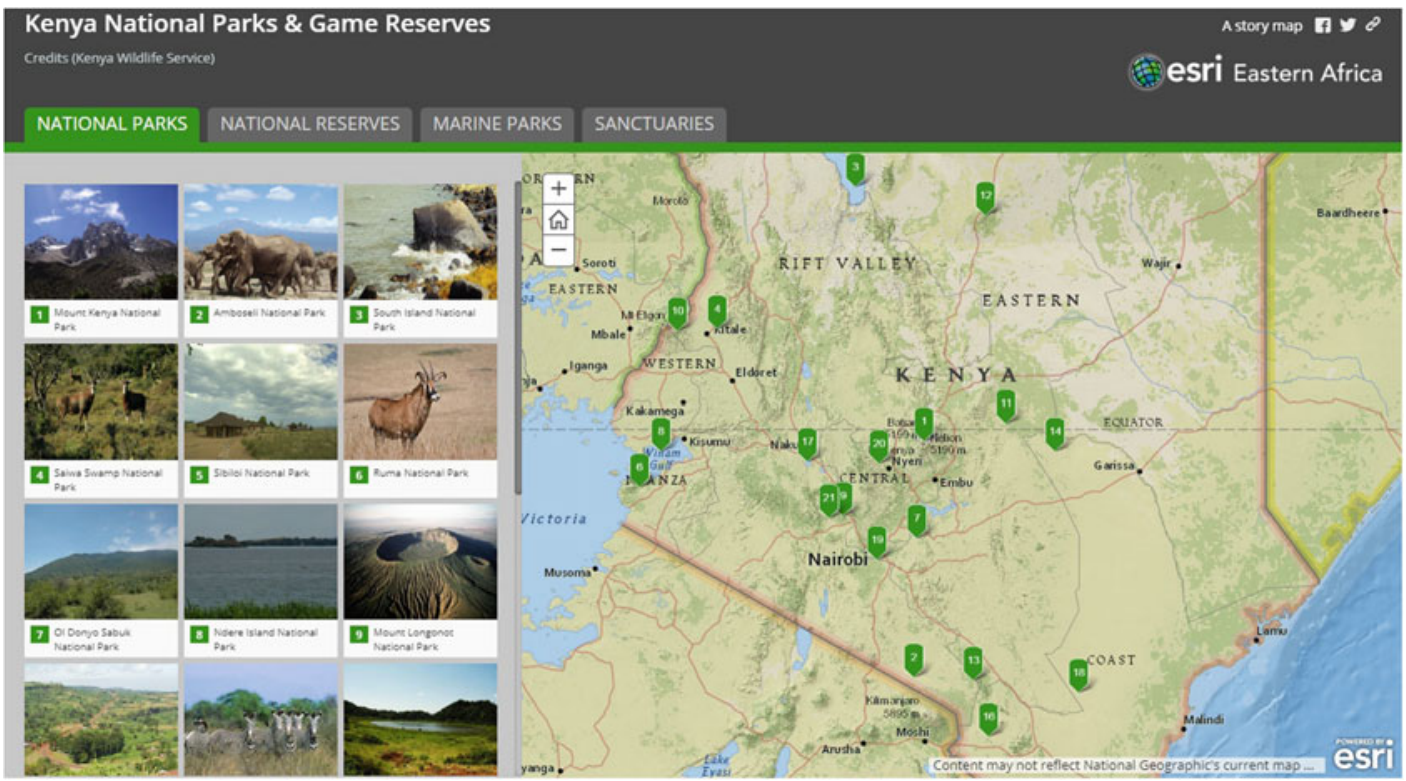

Fig. 10.2 Example of the Shortlist template. (Source: Esri Eastern Africa 2018) 


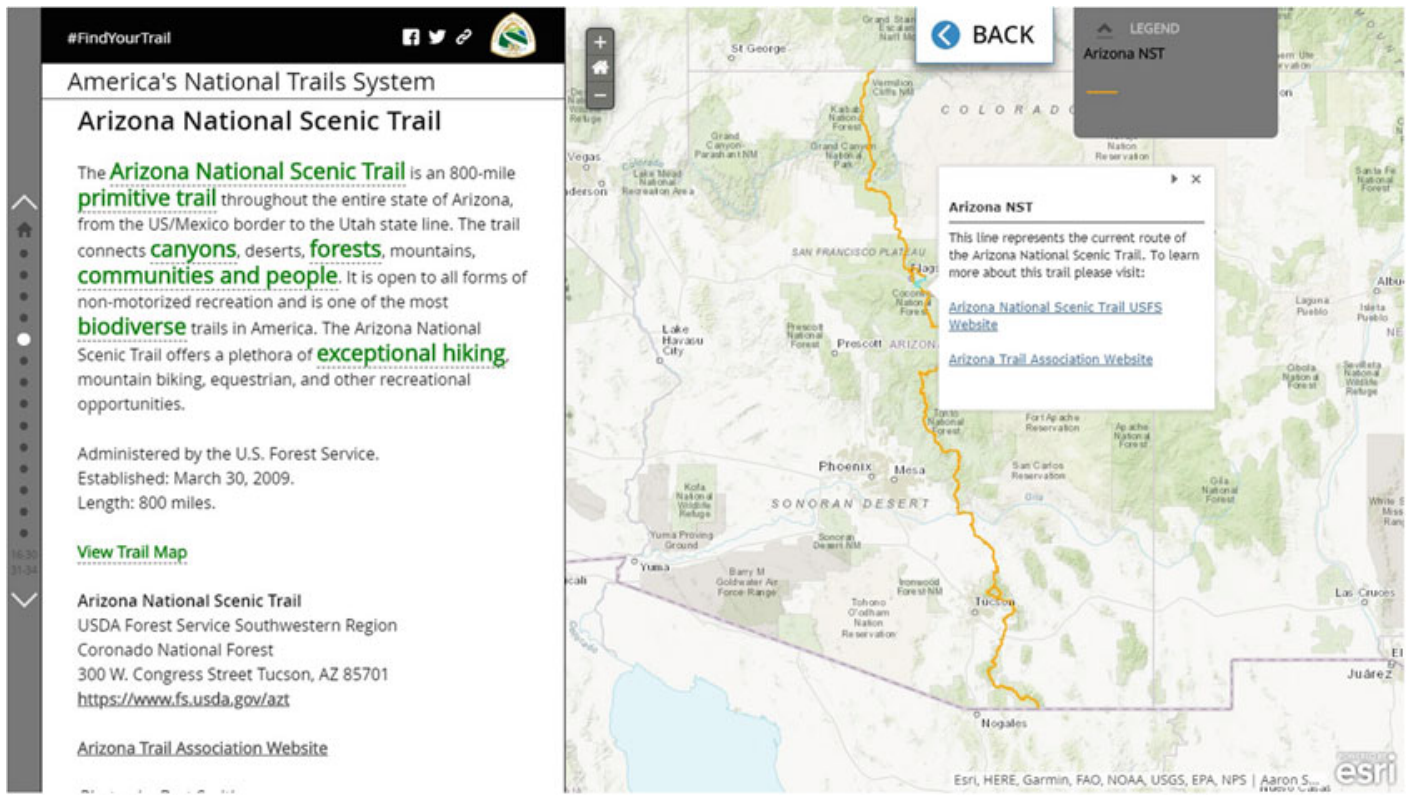

Fig. 10.3 Example of the Map Journal template. (Source: US National Park Service 2018)

Fusion Tables in the research (Bowie et al. 2014; Signore 2016). Fusion Tables enables to upload tabular data (spreadsheets, CSV, KML) and visualise them in many ways (pie charts, bar charts, lineplots, scatterplots, timelines, and maps). Visualisation is based on Google Maps (street, satellite, and terrain) that also allows to geocode the input data without coordinates (e.g. geocoding of postal addresses into point in the map). Fusion Tables also supports the rendering of heat maps (maps of the density of features). Data and all results can be shared and also exported in many graphic, tabular and GIS formats (KML). All users have $1 \mathrm{~GB}$ of storage quota for their tables. There exist also API that allows external developers to design applications using Fusion tables (Fig. 10.4). Fusion Tables are available at https://fusiontables.google.com, but will not be available after December 2019.

\subsection{Google Maps API}

Google Maps is a web mapping service developed by Google. Google Maps also offers an API (Application programming interface), that can be used for development custom web mapping applications based on Google Maps (including different map types, Street View, geocoding services or route planning tools). API is based on the JavaScript and allows to create maps with your own content and imagery for display on web pages and mobile devices. There exist many online tutorials how to start to use Google Maps API, that allows to use it also for programming beginners. Google Maps API is a payed service, but Google offers $\$ 200$ monthly credit that is good enough for creation of many basic map applications. Google maps have been used in many research fields like health studies (Boulos 2005), logistics (Fu et al. 2010), GPS navigation (Li and Zhijian 2010), or participatory mapping (Boroushaki et al. 2010) (Fig. 10.5).

\subsection{QGIS Cloud}

QGIS Cloud is a powerful Web-GIS platform for publishing and sharing maps, data and services on the internet (Sourcepole AG 2018). The main idea of QGIS cloud is a direct connection between desktop QGIS application and online QGIS 


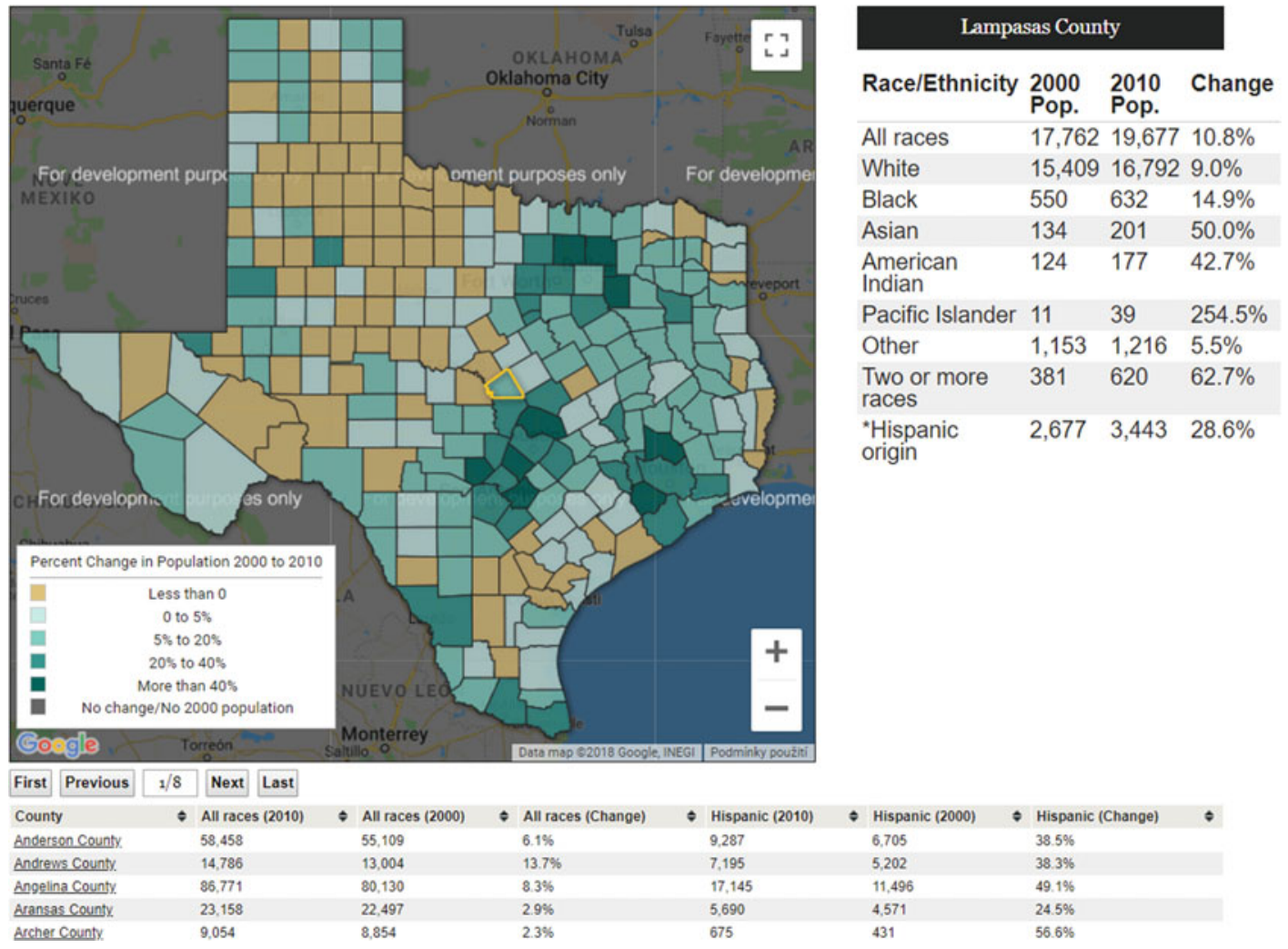

Fig. 10.4 Example of use of Google Fusion Tables for Census data visualisation. (Source: Murphy and Stiles 2012)

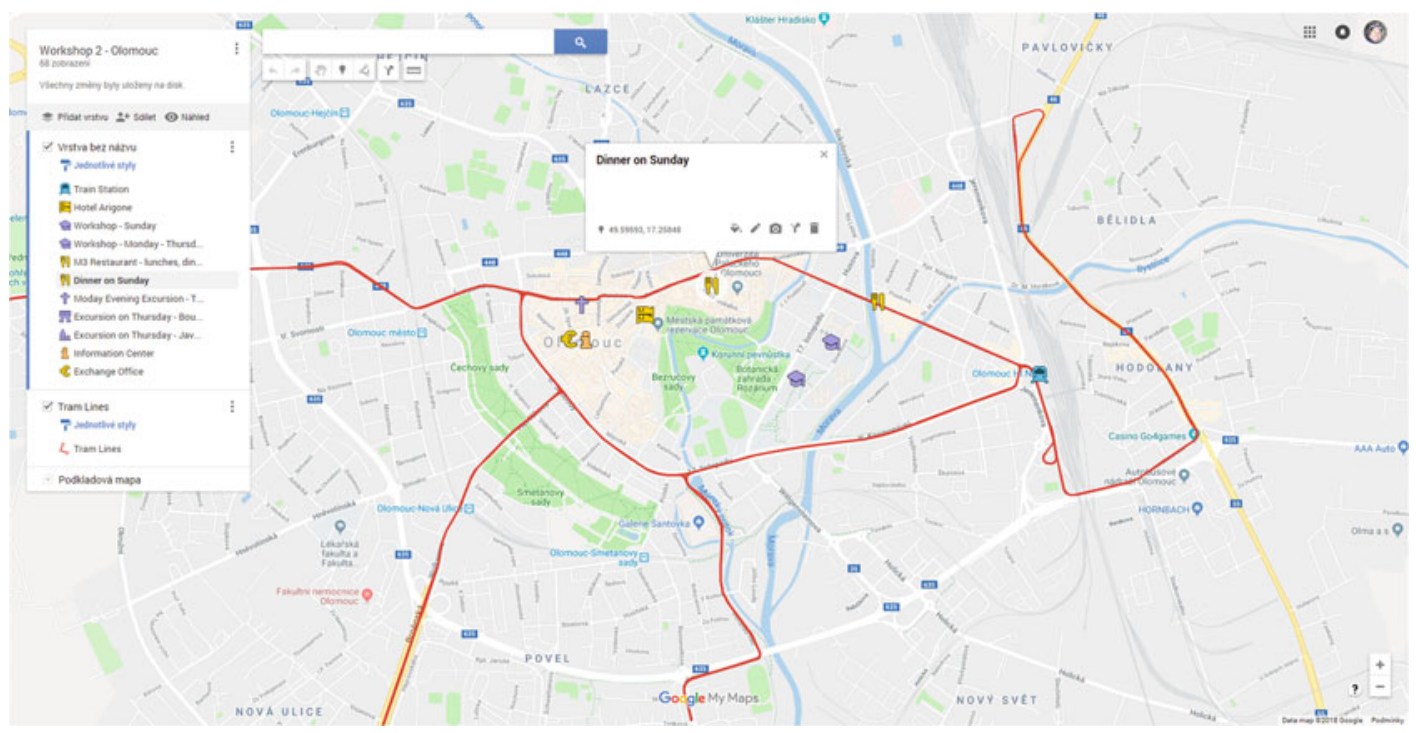

Fig. 10.5 Example of Google Maps API used for private purposes - conference organisation. (Source: Authors) 
cloud. This is realised through the QGIS Cloud plugin from the official QGIS plugin repository. Thanks to this connection, the application can be prepared as a map in QGIS environment and transferred to the web at the end. Maps can be shared over OGC (Open Geospatial Consortium) compliant web services. Maps can be displayed via WMS or downloaded via WFS. With WFS-T, you can edit your data directly over the web service. There exist also the Mobile Client integrated in QGIS Cloud. If the data should not be publicly accessible, QGIS Cloud pro allows you to restrict access by protecting the resources with a password. A free account offers unlimited public maps (only non-commercial/non-government use) and one PostGIS 2.0 database (max. $50 \mathrm{MB}$ total, max 10 concurrent database connections). Payed QGIS Cloud Pro version offers more databases, more space and many additional functions (Fig. 10.6). QGIS Cloud is available at https://qgiscloud.com/.

\subsection{Leaflet}

Leaflet is the leading open-source JavaScript library for mobile-friendly interactive maps. Leaflet has many mapping features that can be used for development simple or very complex web mapping applications. Leaflet is designed with simplicity, performance and usability in mind. It works efficiently across all major desktop and mobile platforms, can be extended with lots of plugins, has a beautiful, easy to use and welldocumented API and a simple, readable source code that is a joy to contribute to (Agafonkin 2017) (Fig. 10.7). It is used for the main OpenStreetMap website map, as well as on many other websites like Flickr, Washington Post, The Wall Street Journal or Geocaching. com. Leaflet is available at https://leafletjs.com/.

\subsection{Mapbox}

Mapbox is a large provider of custom online maps for websites and applications such as Foursquare, Lonely Planet, Facebook, the Financial Times, The Weather Channel and Snapchat. Mapbox is the creator of, or a significant contributor to some open source mapping libraries and applications, including the MBTiles specification, the TileMill cartography IDE, the Leaflet JavaScript library, and the CartoCSS map styling language and parser (Mapbox 2018). The Mapbox Maps SDK allows advanced map customisation. The developer can choose among several Mapbox-designed styles or design a

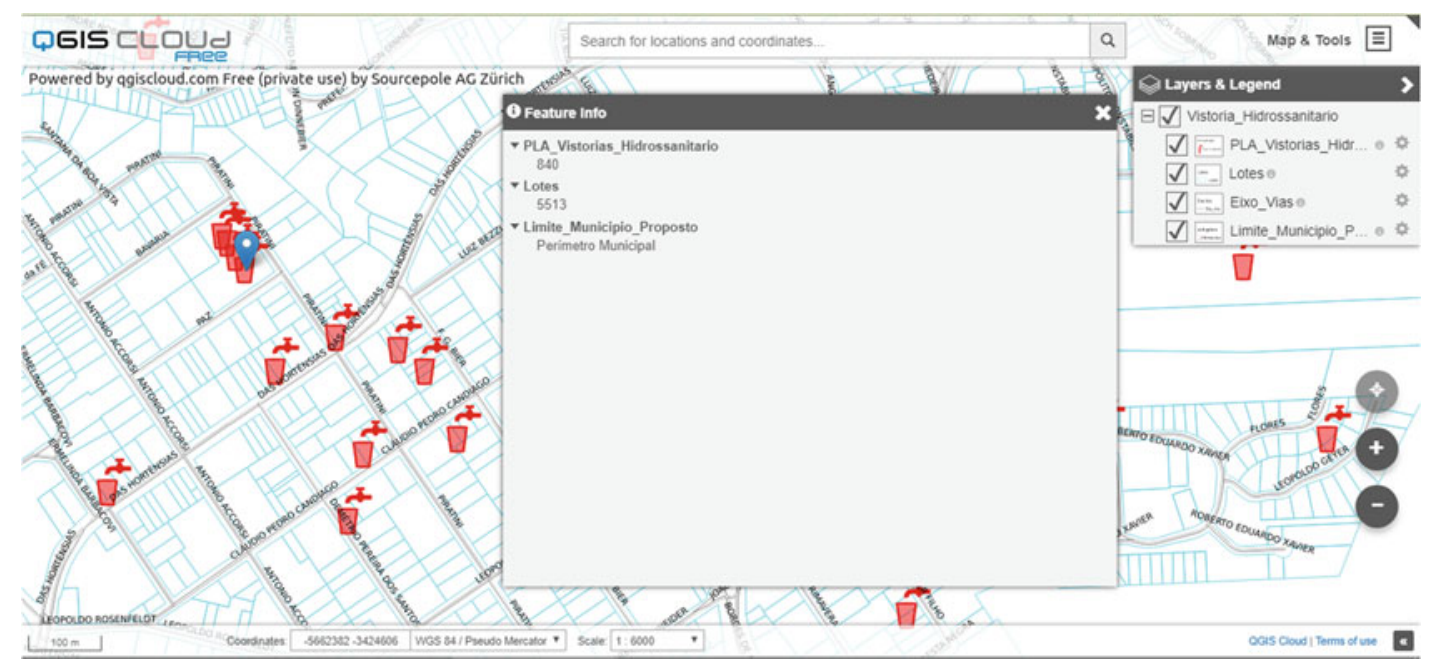

Fig. 10.6 Example of QGIS Cloud application. (Source Sourcepole AG 2018) 


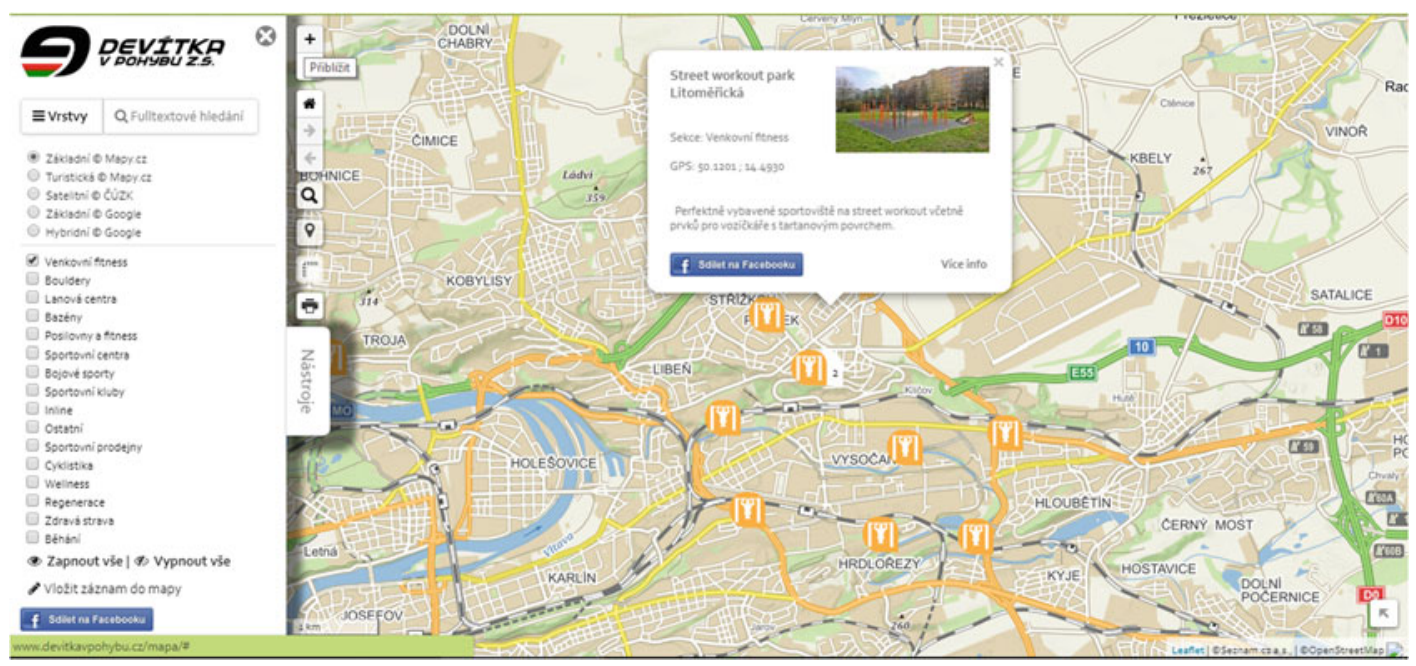

Fig. 10.7 Example of QGIS Cloud application. (Source: Nétek 2016)

custom style in the graphical style editor of Mapbox Studio (Mapbox GL 2018). Mapbox is a payed service, but if you will not exceed some limits (map views, page requests), you can use it for free (Fig. 10.8).

\subsection{Carto}

CARTO (formerly CartoDB) is a Software as a Service (SaaS) cloud computing platform that provides GIS and web mapping tools for display in a web browser (Wikipedia 2018). Use of CARTO for data analysis and visualization that do not require previous GIS or development experience. CARTO users can use the company's free platform or deploy their own instance of the open source software. For smaller amount of data, CARTO is offered as free service. CARTO is built on PostGIS and PostgreSQL. The tool uses JavaScript extensively in the front end web application, back end Node.js based APIs, and for client libraries (CartoDB 2011) (Fig. 10.9).

\subsection{OpenLayers}

OpenLayers is an open-source JavaScript library for creation of dynamic web maps. It can display map tiles, vector data and markers loaded from any source. OpenLayers has been developed to further the use of geographic information of all kinds (OpenLayers 2018). It is completely free, Open Source JavaScript, released under the 2-clause BSD License (also known as the FreeBSD). OpenLayers supports GeoRSS, KML (Keyhole Markup Language), Geography Markup Language (GML), GeoJSON and map data from any source using OGC-standards as Web Map Service (WMS) or Web Feature Service (WFS). API is provided for building custom web map applications (Fig. 10.10).

\subsection{Advanced Mapping Tools}

Except the tools mentioned above there exist many advanced web mapping software or environment that allows to create very advanced web map applications with very specific tools. Currently, there are two leading open source platforms - MapServer (https://mapserver.org/) and GeoServer (http://geoserver.org/). These are used mostly by GIS professionals and requires more complex programming skills. MapServer and GeoServer represents classical mapping server with a huge variety of GIS functions for data management, analysis and visualisation. In comparison with simple mapping tools, map servers have many benefits. They offer advanced 


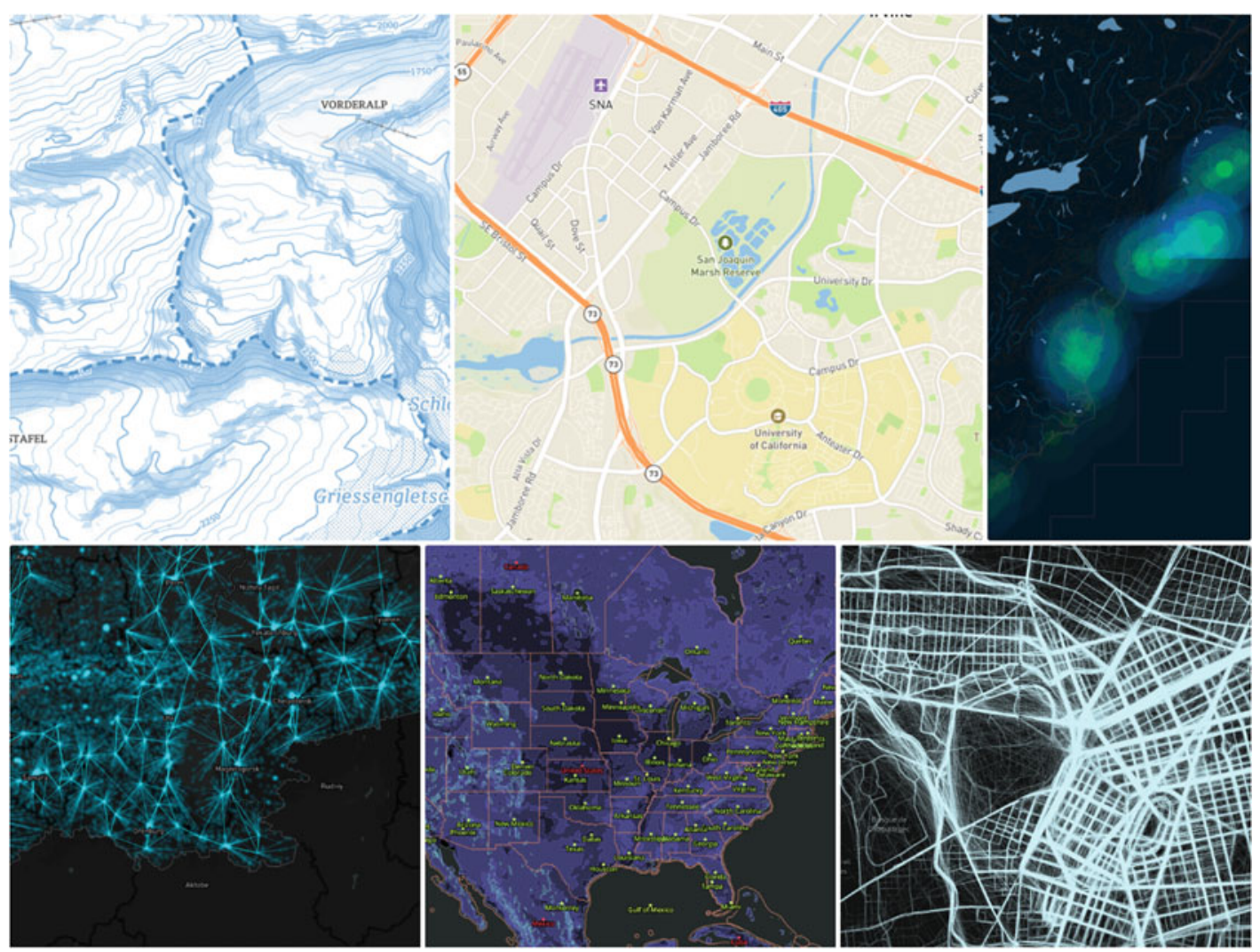

Fig. 10.8 Examples of Mapbox customisation. (Source: Mapbox 2018)

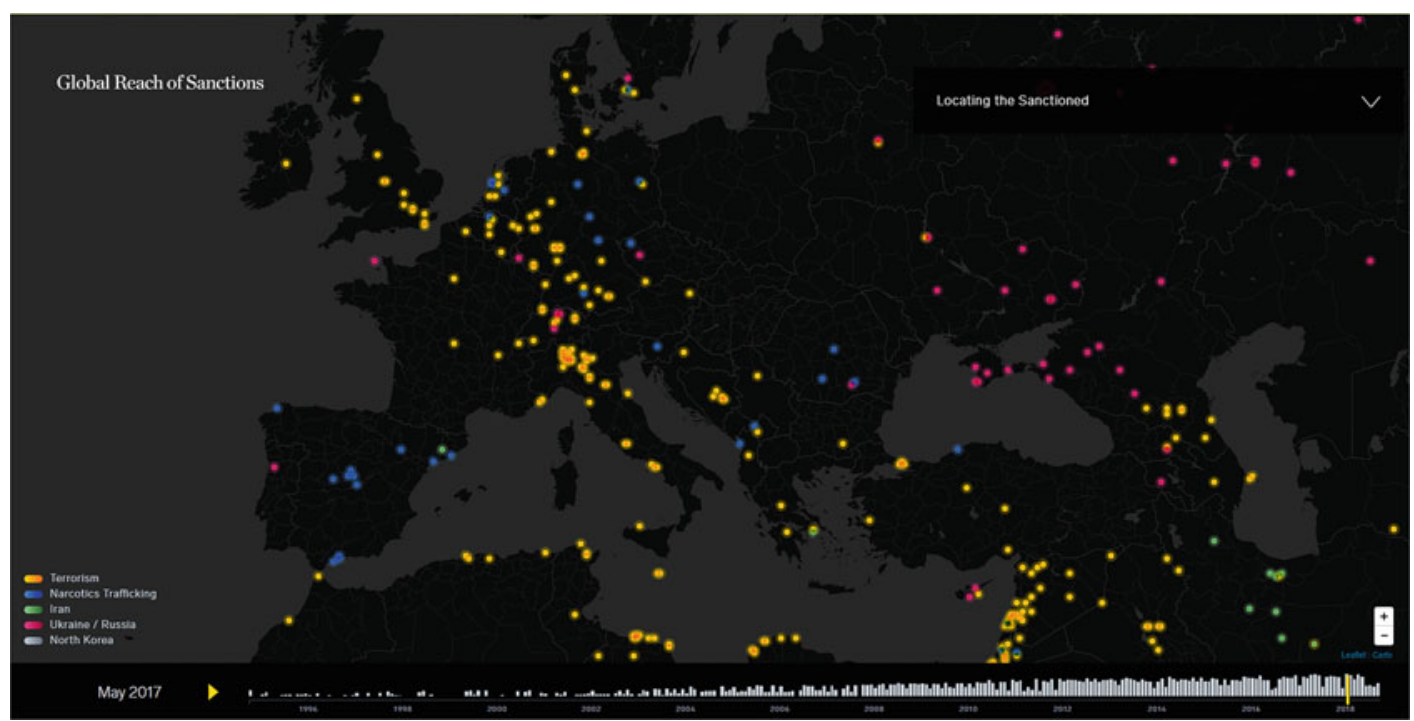

Fig. 10.9 Example of use of CARTO for sanctions visualisation. (Source: EnigmaPublic 2018) 


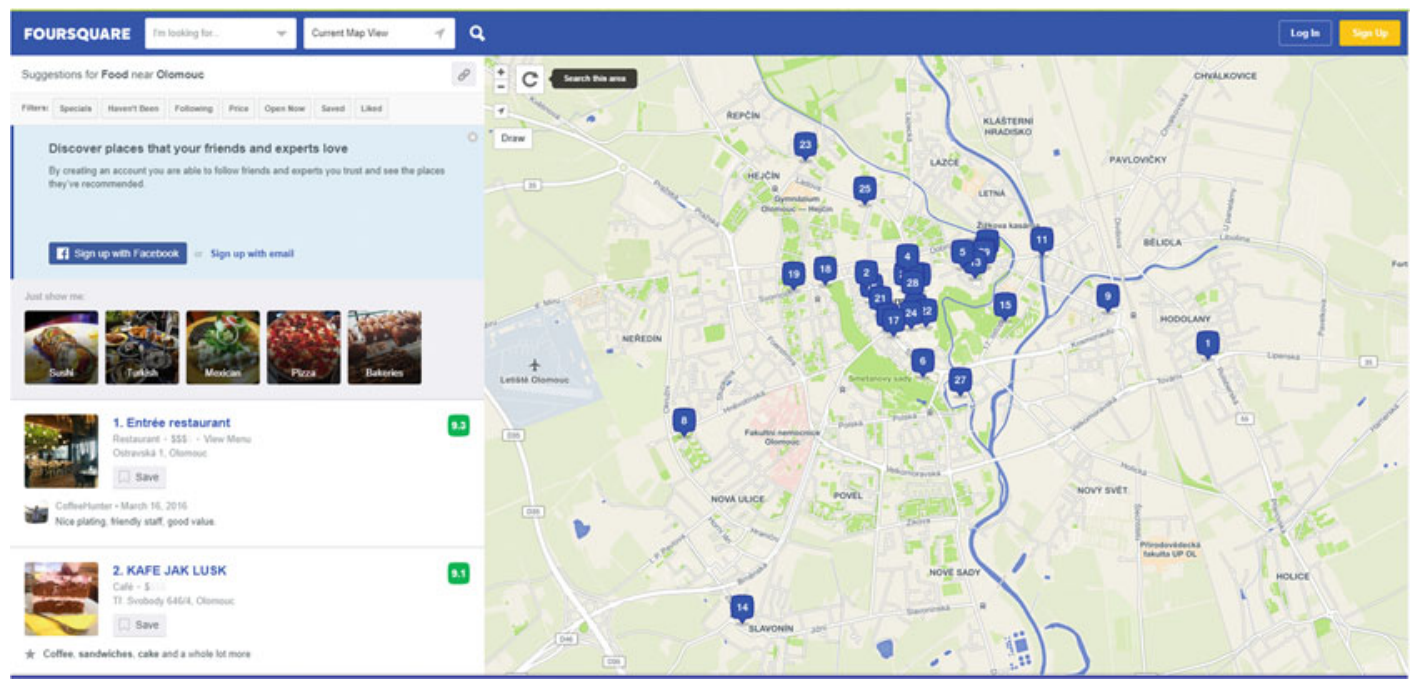

Fig. 10.10 Example of use of OpenLayers. (Source: Foursquare 2018)

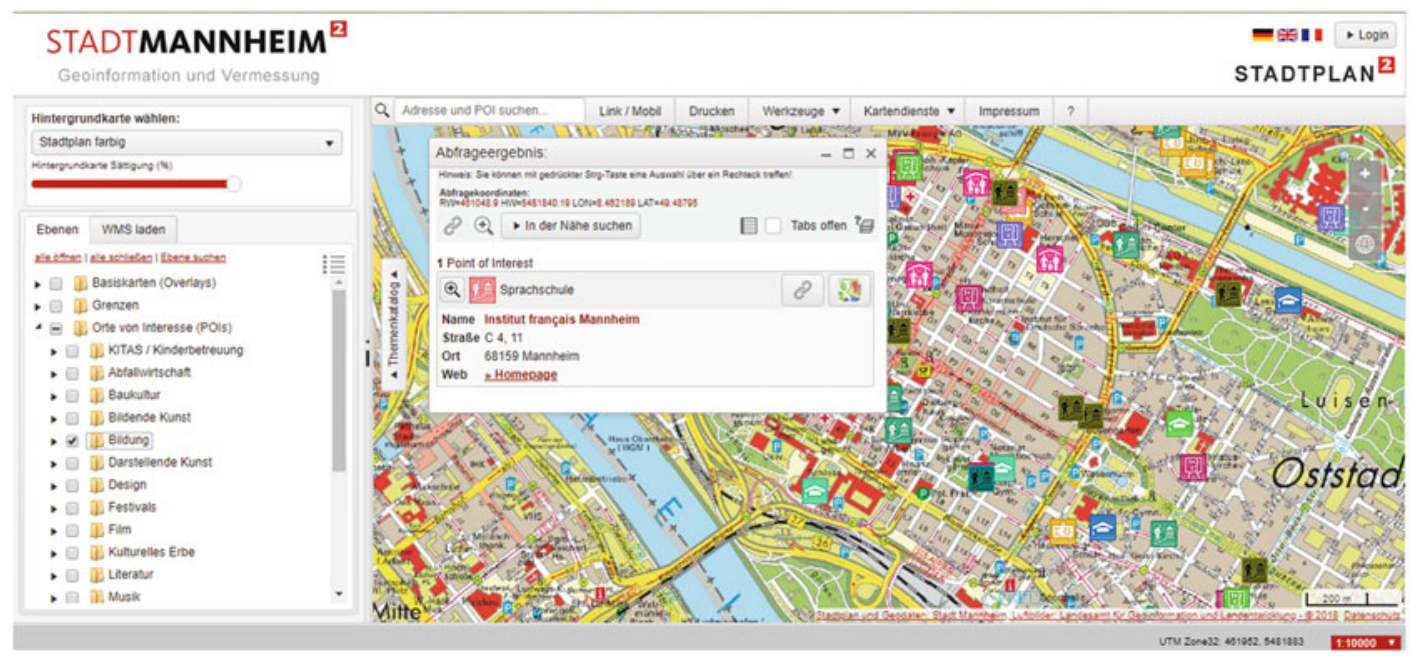

Fig. 10.11 Example of MapServer Application. (Source: Mannheim 2018)

cartographic options like displaying data dynamically, cartographic projections, professional symbol styling, different spatial data formats support, or publishing mapping services (e.g. WMS and WFS) (Fig. 10.11).

\section{References}

Abrate, M., Bacciu, C., Hast, A., et al. (2013). GeoMemories-A platform for visualizing historical, environmental and geospatial changes in the Italian landscape. ISPRS Int $J$ Geo-Information, 2, 432-455. 
Agafonkin, V. (2017). Leaflet - A JavaScript library for interactive maps. https://leafletjs.com/. Accessed 3 Dec 2018.

Apostolopoulos, K., Geli, M., Petrelli, P., et al. (2016). A new model for cadastral surveying using crowdsourcing. Survey Review, 50, 1-12. https://doi. org/10.1080/00396265.2016.1253522.

ArcGIS Blog. (2018). Story map crowdsource moves to mature support in June 2018.

Boroushaki, S., Malczewski, J., Boroushaki, S., \& Malczewski, J. (2010). Participatory GIS: A web-based collaborative GIS and multicriteria decision analysis. In Urisa J.

Boulos, M. N. K. (2005). Web GIS in practice III: Creating a simple interactive map of England's strategic health authorities using Google maps API, Google earth KML, and MSN virtual earth map control. International Journal of Health Geographics, 4(1), 1-8.

Bowie, G. D., Millward, A. A., \& Bhagat, N. N. (2014). Interactive mapping of urban tree benefits using Google fusion tables and API technologies. Urban Forestry \& Urban Greening, 13, 742-755. https:// doi.org/10.1016/j.ufug.2014.06.002.

CartoDB. (2011). CartoDB code repository. carto.com/ docs. Accessed 4 Dec 2018.

Cho, N., \& Kang, Y. (2017). Space-time density of field trip trajectory: Exploring spatio-temporal patterns in movement data. Spatial Information Research, 25, 141-150. https://doi.org/10.1007/s41324-016-0079-x.

Coleman, B., et al. (2015). History storytelling with Esri's story maps application. Teaching History, 49, 60.

Crocker, S., Walters, B., \& Morin, R. (2015). Visual analysis of forest health using story maps: A tale of two forest insect pests. In S. M. Stanton \& G. Christensen (Eds.), Pushing boundaries: New directions in inventory techniques and applications: Forest inventory and analysis (FIA) symposium 2015 (p. 315). Portland: Department of Agriculture, Forest Service, Pacific Northwest Research Station.

Edsall, R. M., Barbour, L., \& Hoffman, J. (2015). Complementary methods for citizen mapping of ecosystem services: Comparing digital and analog representations (pp. 295-307). Cham: Springer.

EnigmaPublic. (2018). Sanctions tracker. https://labs. enigma.com/sanctions-tracker/. Accessed 4 Dec 2018.

Esri. (2018a). What is ArcGIS online?

Esri. (2018b). Story Map Crowdsource (Mature).

Esri Eastern Africa. (2018). Kenya National Parks \& Game Reserves.

Foursquare. (2018). Foursquare. https://foursquare.com. Accessed 4 Dec 2018.

Fox, C. (2016). The value of story mapping for coastal managers. University of Rhode Island.
Fu, C., Wang, Y., Xu, Y., \& Li, Q. (2010). The logistics network system based on the google maps API. In 2010 International Conference on Logistics Systems and Intelligent Management, ICLSIM 2010.

Gonzalez, H., Halevy, A., Jensen, C. S., et al. (2010). Google fusion tables: Data management, integration and collaboration in the cloud. In Proceedings of the 1st ACM symposium on Cloud Computing - SoCC ' 10.

Kerski, J. (2013). Understanding our changing world through web-mapping based investigations. J Res Didact Geogr, 2, 11-26.

Kerski, J. (2015). Geo-awareness, geo-enablement, geotechnologies, citizen science, and storytelling: Geography on the world stage. Geography Compass, 9, 14-26.

Kolvoord, R., Keranen, K., \& Rittenhouse, P. (2017). Applications of location-based services and mobile technologies in $\mathrm{K}-12$ classrooms. ISPRS Int $J$ Geo-Inf, 6, 209. https://doi.org/10.3390/ijgi6070209.

Li, H., \& Zhijian, L. (2010). The study and implementation of mobile GPS navigation system based on Google maps. In Proceedings of ICCIA 2010-2010 international conference on computer and information application.

Mannheim. (2018). Stadtplan Mannheim. https://www. gis-mannheim.de/mannheim/index.php. Accessed 4 Dec 2018.

Mapbox. (2018). Mapbox. https://www.mapbox.com/ about/team/. Accessed 4 Dec 2018.

Mapbox GL. (2018). Mapbox GL - OpenStreetMap Wiki. https://wiki.openstreetmap.org/wiki/Mapbox_GL. Accessed 4 Dec 2018.

Mourafetis, G., Apostolopoulos, K., Potsiou, C., \& Ioannidis, C. (2015). Enhancing cadastral surveys by facilitating the participation of owners. Survey Review, 47, 316-324. https://doi.org/10.1179/1752270615Y. 0000000009 .

Murphy, R., \& Stiles, M. (2012). Census 2010 interactive map: Texas population by race, Hispanic origin. The Texas Tribune.. https://www.texastribune.org/library/ data/census-2010/. Accessed 3 Dec 2018.

Nétek, R. (2016). Devítka v pohybu-mapa.. http://www. devitkavpohybu.cz/mapa/. Accessed 3 Dec 2018.

OpenLayers. (2018). OpenLayers.. https://openlayers.org/. Accessed 4 Dec 2018.

Pánek, J., \& Glass, M. (2018). Gaining a mobile sense of place with collector for ArcGIS. Journal of Geography in Higher Education, 1-14. https://doi.org/10.1080/ 03098265.2018.1515190.

Peirce, S. (2016). Making learning Mobile: Using Mobile technologies to bring GIS into the geography classroom. Teach Innov Proj, 6, 1.

Signore, A. (2016). Mapping and sharing agrobiodiversity using open data kit and Google fusion 
tables. Computers and Electronics in Agriculture, 127, 87-91. https://doi.org/10.1016/j.compag.2016.06.006.

Smith, D. A. (2016). Online interactive thematic mapping: Applications and techniques for socio-economic research. Computers, Environment and Urban Systems, 57, 106-117.
Sourcepole AG. (2018). QGIS cloud.. https://qgiscloud. com/. Accessed 3 Dec 2018.

US National Park Service. (2018). America's National Trails System.

Wikipedia. (2018). CartoDB.. https://en.wikipedia.org/ wiki/CartoDB. Accessed 4 Dec 2018.

Open Access This chapter is licensed under the terms of the Creative Commons Attribution 4.0 International License (http://creativecommons.org/licenses/by/4.0/), which permits use, sharing, adaptation, distribution and reproduction in any medium or format, as long as you give appropriate credit to the original author(s) and the source, provide a link to the Creative Commons licence and indicate if changes were made.

The images or other third party material in this chapter are included in the chapter's Creative Commons licence, unless indicated otherwise in a credit line to the material. If material is not included in the chapter's Creative Commons licence and your intended use is not permitted by statutory regulation or exceeds the permitted use, you will need to obtain permission directly from the copyright holder. 